\title{
Influence of the composition of hydroxypropyl cellulose/maleic acid-alt-styrene copolymer blends on their properties as matrix for drug release
}

\author{
G. G. Bumbu ${ }^{1,3}$, B. S. Munteanu ${ }^{2}$, J. Eckelt ${ }^{3}$, C. Vasile $^{3 *}$ \\ 1P. Poni Institute of Macromolecular Chemistry, Physical Chemistry of Polymer Laboratory, 41A Grigore Ghica Voda \\ Alley, Ro 700487, Iasi, Romania \\ 2‘Al. I. Cuza' University, Faculty of Physics, 16 Carol I Blvd. Iasi, Romania \\ ${ }^{3}$ University of Mainz, Institute of Physical Chemistry, 55099 Mainz, Germany
}

Received 25 January 2009; accepted in revised form 3 March 2009

\begin{abstract}
Poly(carboxylic acid)-polysaccharide compositions have been found suitable for obtaining drug formulations with controlled release, most formulations being therapeutically efficacious, stable, and non-irritant. The influence of the characteristics of the aqueous solutions from which the polymer matrix is prepared (i.e. the total concentration of polymer in solutions and the mixing ratio between the partners, hydroxypropyl cellulose, HPC and maleic acid-alternating-styrene copolymer, MAc-alt-S) on the kinetics of some drugs release in acidic environment $(\mathrm{pH}=2)$ has been followed by 'in vitro' dissolution tests. It has been established that the kinetics of procaine hydrochloride release from HPC/MAc-alt-S matrix depends on its composition; the diffusion exponent, $n$ is close to 0.5 for matrices where one of the components is in large excess and $n \sim 0.02$ for middle composition range. The lower value of diffusion exponent for middle composition range could be caused by the so called 'burst effect', therefore the kinetic evaluation is difficult.
\end{abstract}

Keywords: biopolymers, interpolymeric association, maleic copolymer, drug release

\section{Introduction}

The design of interpolymeric complexes, which can be used for the immobilization of various drugs, hormones, enzymes, and proteins is of considerable interest because of the possibility of developing different controlled release systems.

Polysaccharides have several advantages as components in drug delivery systems. They are natural or semi-synthetic polymers showing a good biocompatibility with living cells. Blend of polysaccharides with synthetic water-soluble polymers lead to materials with improved physico-chemical and mechanical characteristics [1].

Several reports were devoted to the development of various drug dosage forms based on poly(car- boxylic acid)-polysaccharide compositions indicating good results in the release of morphine sulfate [2], propranolol hydrochloride [3], carbamazepin [4], model peptide peroxidase [5], lidocaine [6] amoxillin and rifampicin, insulin [7], levomycetin $[8,9]$, proteins, lactate dehydrogenase [10], phenacetin [11], timolol maleate for ophthalmology application [12], antibacterial agent, ofloxacin [13] and many others. Most formulations were therapeutically efficacious, stable, and nonirritant [14]. The complexes based on poly(acrylic acid), PAA and methyl or hydroxypropyl methyl cellulose demonstrated very good ability to form capsules insoluble in acid media [15]. 
Satoh and co-workers [16] studied the bioadhesive properties of tablets consisting of hydroxypropyl cellulose (HPC) and carboxyvinyl polymer (CP) using mouse peritoneal membrane containing bleomycin hydrochloride, carboquone, and 5-fluorouracil and they found them favorable for the treatment of foci in the cervical canal.

In a previous work we showed that HPC and MAcalt-S copolymer form interpolymeric complexes, IPC via hydrogen bonding interactions between the oxygen of the ether groups of HPC and the $\mathrm{OH}-$ groups of the carboxyl groups of MAc-alt-S $[17,18]$, IPC stabilized by hydrophobic interactions between the isopropyl side chain of HPC and the styrene groups of MAc-alt-S [19]. The stoichiometry of the interpolymeric complex was estimated to be HPC/MAc-alt-S $=40: 60 \quad[\mathrm{w} / \mathrm{w}]$ independent of the total polymer concentration in the system, $c_{p o l}$. At $c_{p o l}=5 \mathrm{mg} \cdot \mathrm{ml}^{-1}$, the mixtures with a content of HPC in the initial mixtures between 20 and $60 \mathrm{wt} \%$, phase separate. At $c_{p o l}=10 \mathrm{mg} \cdot \mathrm{ml}^{-1}$, depending on the mixing ratio between the partners, either a phase separation (in the mixtures with a prevailing content of one of the components) or a gelation (similar mixing ratio between components) occurs. The IR spectra indicated that there is a tendency of the MAc-alt-S, independent of the mixing ratio of the components, to accumulate in the gel until it reaches a concentration of around $60 \mathrm{wt} \%$. The maximum concentration of the precipitate in the gel phase is also reached at a mixing ratio between HPC and MAcalt-S of 40/60 that corresponds to the stoichiometry of the complex. At pH lower than 4.5 the HPC/ MAc-alt-S, IPC becomes water-insoluble [18].

It is well known from membrane science that the morphology and therefore the permeability and transport characteristics highly depend on the way of preparation [20]. Also in mixtures that can form IPCs, it is expected that when one of the components is in large excess, the structure of the interpolymer associations to be different to the mixtures where the ratio between the components is close to the stoichiometry, therefore a different morphology and release profile of the drug is expected.

In this work, it is investigated the influence of the characteristics of the aqueous solutions from which the polymer matrix is prepared, i.e. the total concentration of polymer in solutions and the mixing ratio between the partners, hydroxypropyl cellulose and maleic acid-alternating-styrene copolymer, on the kinetics of the various drugs released in acidic environment $(\mathrm{pH}=2)$. Three drugs with different structure, molecular weight and solubility have been incorporated in the HPC/MAc-alt-S matrices, namely: procaine hydrochloride, vanillin and tannic acid.

Procaine hydrochloride, known also as novocaine, it is a local anaesthetic from the amino ester group, mainly used to reduce the pain of intramuscular infections, in stomatology, etc. It acts by constriction of blood vessels determining the bleeding reduction without generating a euphoric state or dependence. Procaine blocks the generation and transmission of the nervous impulses by lowering the membrane permeability to the ions, inhibiting the depolarization and so loosing of pain sensation. Procaine is also the main ingredient in the preparation of the Gerovital H3 known to slow down the aging effects. From theoretical point of view procaine is often used as model drug in many drug release experiments.

Vanillin (4-hydroxy-3-methoxybenzaldehyde) is efficacious for the treatment of chronic hypoacidic gastritis and chronic non-acid gastritis. As well as this receptor inhibition, in the central nervous system, vanillin also influences the craving to consume food. In this context it is supposed that the vanillin is able to increase the concentration of the neurotransmitter serotonin in the brain [21]. Increased brain serotonin concentration, however, leads demonstratively to a reduced craving to consume food.

Tannic acid can be used for medical purposes such as: anti-diarrhoea, hemostats and anti-piles compounds, while together with other related compounds as those containing galic and elagic acids (epigalitaninuri) are inhibitors in HIV replications. It has anti-bacterial properties and is a very beneficial anti-oxidant. In high quantities it slows down the absorption of iron and possibly other trace minerals. The use of tannic acid as an adjuvant therapy for burn wounds has regained interest in present times. In particular, some preclinical and clinical studies indicate that highly purified tannic acids can provide a valuable tool to improve wound healing and to reduce scar tissue formation, it induces a durable, supple crust that did not obstruct the regular outgrowth of epithelium. The assumed hepatotoxicity of tannic acid is questioned [22]. 


\section{Experimental}

\subsection{Materials}

Hydroxypropyl cellulose LF, Klucel ${ }^{\mathrm{TM}}$, a food grade polymer, offered by courtesy of Aqualon Company, Hopewell, Virginia has been used. According to the producer specifications, HPC LF has a molecular mass of approximately $100000 \mathrm{~g} \cdot \mathrm{mol}^{-1}$ and a 3.4 moles of substitution [23]. The main chain of HPC consists of glucopyranosyl units linked in $(1 \rightarrow 4) \beta$ position. The side substituents are formed by short chains containing from one up to six hydroxypropyl units.

Maleic acid-alternating-styrene copolymer (MAcalt-S) was prepared by the hydrolysis of maleic anhydride-alternating-styrene copolymer (MAalt-S) in pure water, at $80^{\circ} \mathrm{C}$ for $4 \mathrm{~h}$. MA-alt-S has been synthesized by free radical copolymerizations, in toluene, at $80^{\circ} \mathrm{C}$ (the detailed synthesis has been described in ref. [24]). The molecular mass of the MAc-alt-S copolymer was calculated based on the molecular mass of the MA-alt-S copolymer as being $130000 \mathrm{~g} \cdot \mathrm{mol}^{-1}$, considering that there are no changes in chain length during hydrolysis. The MAc-alt-S copolymer is totally water-soluble.

Both samples (HPC and MAc-alt-S copolymer) were carefully purified before study by dialysis against water and then freeze dried.

The structure and the water solubility of the used drugs are summarized in Table 1.

Twice-distilled water was used as solvent for all measurements. The $\mathrm{pH}$ of the solutions was adjusted at value 2 with diluted $\mathrm{HCl}$ solution in twice-distilled water.

Procaine hydrochloride, vanillin and tannic acid were purchased from Sigma Aldrich and used as received.

Table 1. Characteristics of the used drugs

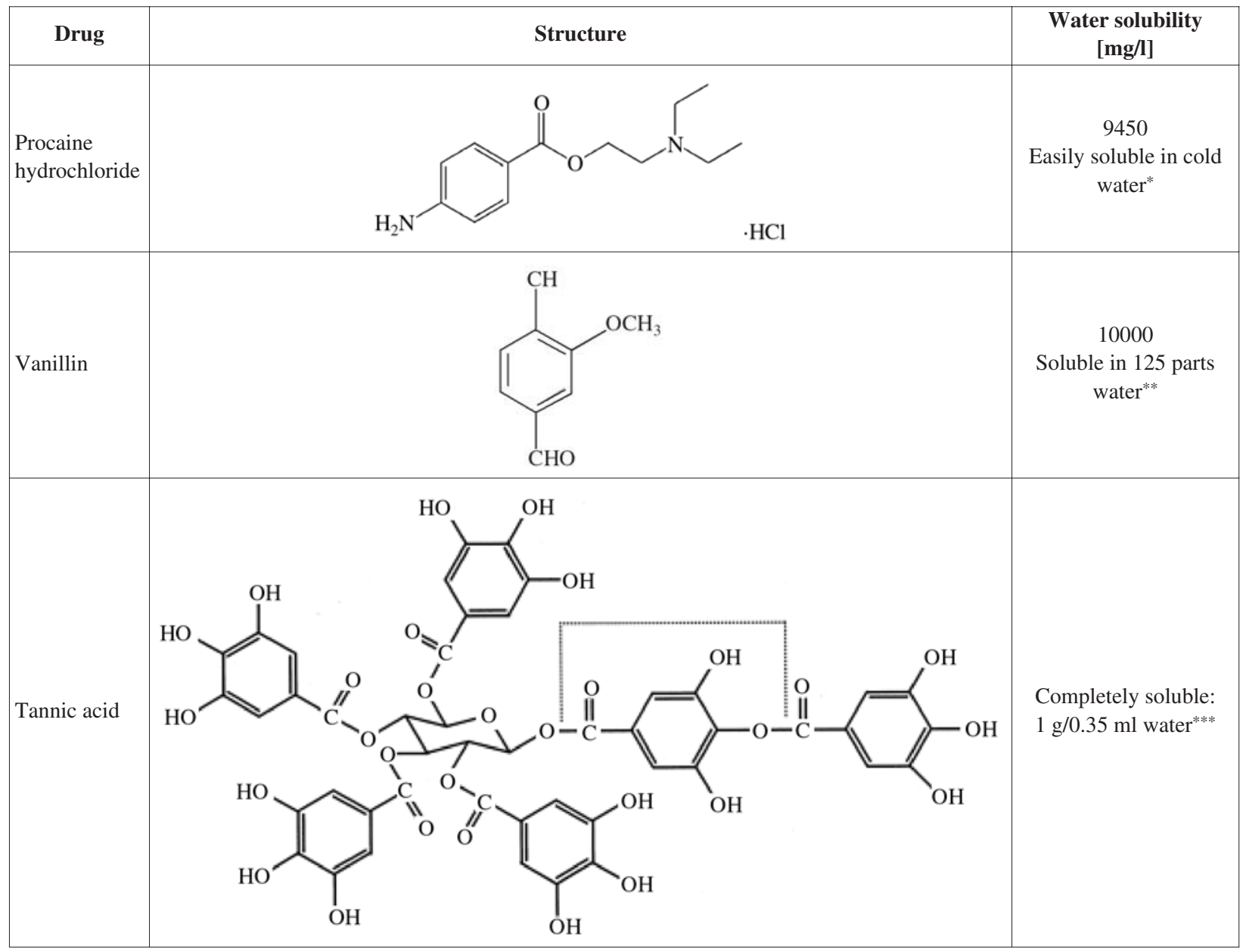

*Science Laboratories, http://www.sciencelab.com/xMSDS-Procaine hydrochloride-9924715;

Mallinckrodt Baker Inc. Materials safety data sheet

**http://www.jtbaker.com/msds/englishhtml/v2775.htm

***http://www.jtbaker.com/msds/englishhtml/t0065.htm 


\subsection{Preparation of the IPC/drug systems}

The drugs were incorporated in the polymeric matrix of HPC, MAc-alt-S or their mixtures at different mixing ratios, at a weight ratio between matrix and drug of 4 to 1 . As MAc-alt-S forms a precipitate with procaine hydrochloride, the samples were prepared as followed: the corresponding amount of drug was previously dissolved in the aqueous solution of HPC and then the HPC-drug solution was mixed with the aqueous solution of the MAc-alt-S in different mixing ratios. The obtained samples were frozen at $-50^{\circ} \mathrm{C}$ and freezedried.

The polymer matrix was prepared at the following weight mixing ratios between HPC and MAc-alt-S: 10/90, 40/60, 50/50, 80/20 at two different total polymer concentrations $c_{p o l}=5 \mathrm{mg} / \mathrm{ml}$ and $c_{p o l}=$ $10 \mathrm{mg} / \mathrm{ml}$.

For comparison reasons the same preparation procedure was used to incorporate vanillin and tanic acid in the $40 \mathrm{wt} \% \mathrm{HPC} / 60 \mathrm{wt} \%$ MAc-alt-S matrix at $c_{p o l}=10 \mathrm{mg} / \mathrm{ml}$.

\subsection{Sample characterization}

A Leitz Wetslar microscope, Germany was used to investigate the fluorescence behaviour of the samples at a magnification of $250 \times$.

In vitro release studies have been conducted in a standard dissolution set-up. [25] Aliquots of the medium of $1 \mathrm{ml}$ were withdrawn periodically at predetermined time intervals and analyzed using a Hewlett Packard 8540A spectrophotometer. In order to maintain the solution concentration the sample is reintroduced in the circuit after analyzing. The concentrations of the drug were calculated based on previously measured calibration curves for each drug at their specific maximum absorption wavelengths using solutions of known concentrations in the range of loaded drug. The maximum absorption wavelengths at $\mathrm{pH}=2$ are for procaine hydrochloride at $\lambda_{\max }=292 \mathrm{~nm}$, vanillin at $\lambda_{\max }=$ $229 \mathrm{~nm}$ and tannic acid at $\lambda_{\max }=212 \mathrm{~nm}$.

A simple, semi-empirical equation using Higuchi model was used to analyze kinetically the data regarding the drug release from HPC/MAc-alt-S system at the initial stages (approximately $60 \%$ fractional release) [26-32] (Equation (1)):
$\frac{M_{t}}{M_{\infty}}=k_{H} t^{n}$

where $M_{t} / M_{\infty}$ is the fractional drug release; $M_{t}$ and $M_{\infty}$ are the absolute cumulative amounts of drug released at time $t$ and at infinite time (in this case maximum release amount in the experimental conditions used, at the plateau of the release curves), respectively; $k_{H}$ is the Higuchi dissolution constant that incorporates the characteristics of the macromolecular network system and the drug, and $n$ is the diffusional exponent, which is an indicative of the transport mechanism.

It has been established that for $n=0.5$, the release mechanism follows the Fick's law diffusion. A value of $n=1$, it means that the drug release is independent of time, while when $n$ lies between 0.5 and 1 an anomalous transport is involved [27, 33].

\section{Results and discussion}

The matrices do not exhibit fluorescence or it is very weak for the MAc-alt-S copolymer. In fluorescence microscopy the colour depends on the drug type being brown-to-green for procaine hydrochloride (Figure 1a) transparent-to-light green for vanillin (Figure 1b) and dark-brown-todark blue (Figure 1c) for tannic acid and the aspect (Figures 1a to 1c) indicates a homogenous distribution of the drugs in the matrix.

\subsection{Influence of the drug type}

The release profile of the three drugs, procaine hydrochloride, vanillin, and tannic acid, with different solubility or size from a HPC/MAc-alt-S interpolymeric associations matrix was investigated at $\mathrm{pH}=2$ and $T=37^{\circ} \mathrm{C}$, an environment that simulate the physiological conditions in the stomach, Figure 2. The matrix has a composition of $40 \mathrm{HPC} / 60 \mathrm{MAc}-$ alt-S and it was prepared form a solutions with $c_{p o l}=5$ and $10 \mathrm{mg} / \mathrm{ml}$. The maximum released quantity at $\mathrm{pH}=2$ is lower $(\sim 38 \%)$ when concentration was $5 \mathrm{wt} \%$ in respect with the case when concentration was $10 \%(\sim 58 \%)$, while the release time decreased with increasing concentration. These values depend on the composition of HPC/MAc-alt-S. The kinetic values are evaluated for approximately $60 \%$ of drug released. 
a)

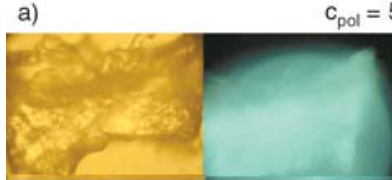

(I)

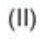

$\mathrm{c}_{\mathrm{pol}}=10 \mathrm{mg} / \mathrm{ml}$

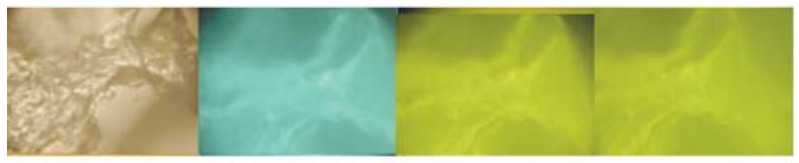

(I)

(II)

(III)

(IV)

b)

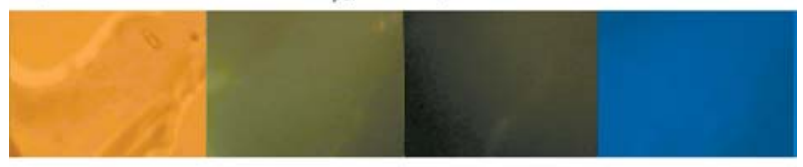

(I)

(II)

(III)

(IV)

c)

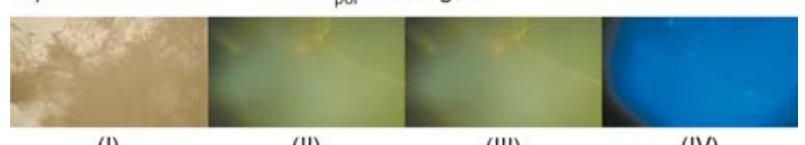

(I)

(II)

(III)

(IV)

Figure 1. a) Microscopical aspects of the 40HPC/60MAcalt-S/procaine hydrochloride system prepared form both a solution with a $c_{p o l}=5 \mathrm{mg} / \mathrm{ml}$ and $c_{p o l}=10 \mathrm{mg} / \mathrm{ml}$ in fluorescence light at various wavelengths of excitation: (I) white light, (II) $380 \mathrm{~nm}$, (III) $410 \mathrm{~nm}$ and (IV) $440 \mathrm{~nm}$. b) Microscopical aspects of the 40HPC/60MAcalt-S/vanillin system prepared form a solution with a $c_{p o l}=10 \mathrm{mg} / \mathrm{ml}$ in fluorescence light at various wavelengths of excitation: (I) white light, (II) $380 \mathrm{~nm}$, (III) $410 \mathrm{~nm}$ and (IV) $440 \mathrm{~nm}$. c) Microscopical aspects of the $40 \mathrm{HPC} / 60 \mathrm{MAc}-$ alt-S/tannic acid system prepared form a solution with a $c_{p o l}=10 \mathrm{mg} / \mathrm{ml}$ in fluorescence light at various wavelengths of excitation: (I) white light, (II) $380 \mathrm{~nm}$, (III) $410 \mathrm{~nm}$ and (IV) $440 \mathrm{~nm}$

One can notice that procaine hydrochloride is released the fastest from the matrix, while the vanillin was the slowest. The equilibrium values of the fractional release are reached after only 14 minutes for procaine hydrochloride while for tannic acid this value is reached after ca. 47 minutes, and vanillin needs about 190 minutes.

The kinetic data obtained by analysing the drug release profile according to Equation (1) are collected in Table 2.

Tannic acid and vanillin have similar release order, therefore similar transport mechanisms. The data for procaine hydrochloride are difficult to analyse,

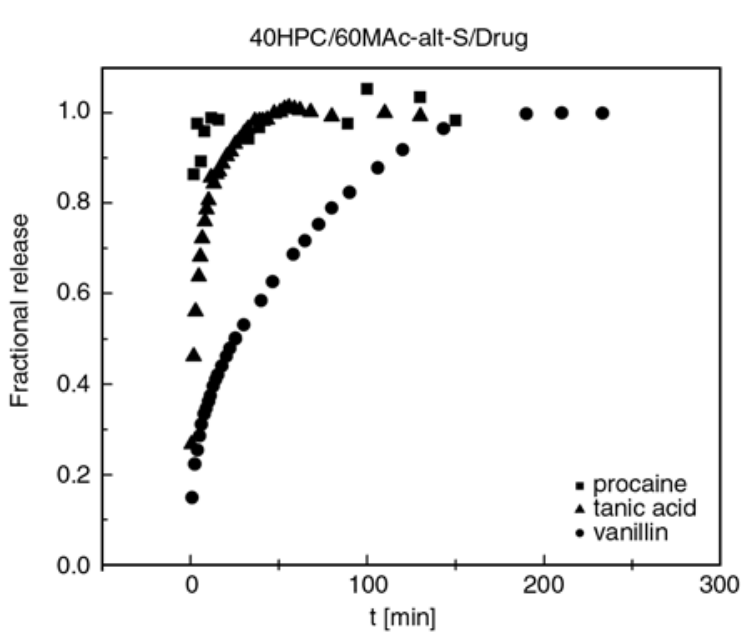

Figure 2. Release profiles of procaine hydrochloride, tannic acid, and vanillin from a 40HPC/60MAcalt-S matrix at $\mathrm{pH}=2$ and $T=37^{\circ} \mathrm{C}$

Table 2. Values of $n$ and $k_{H}$ for various drugs released from a $40 \mathrm{HPC} / 60 \mathrm{MAc}$-alt-S matrix at $\mathrm{pH}=2$ and $T=37^{\circ} \mathrm{C}$

\begin{tabular}{|l|c|c|}
\hline \multicolumn{1}{|c|}{ Drug } & $\mathbf{n}$ & $\mathbf{k}_{\mathbf{H}}\left[\mathbf{m i n}^{-\mathbf{n}}\right]$ \\
\hline Tannic acid & $0.326 \pm 0.008$ & $0.384 \pm 0.006$ \\
\hline Procaine hydrochloride & $0.018 \pm 0.007$ & $0.920 \pm 0.020$ \\
\hline Vanillin & $0.351 \pm 0.003$ & $0.160 \pm 0.001$ \\
\hline
\end{tabular}

as the release of the drug is very fast. It is characterized by a pronounced 'burst effect'.

\subsection{Influence of matrix composition on the release profile}

The fractional release of procaine hydrochloride from matrices with different ratios between HPC and MAc-alt-S is shown in Figures $3 a$ and $3 b$

The release profile of the drug depends both on the ratio between the HPC and MA-alt-S and on the total polymer concentration of the solutions used for the preparation of matrix. For example for the matrix containing $80 \mathrm{HPC} / 20 \mathrm{MAc}-$ alt-S the release time decreases from 175 minutes when the system is prepared from a solution with $c_{p o l}=5 \mathrm{mg} / \mathrm{ml}$ to 100 minutes when it is obtained form $c_{p o l}=$ $10 \mathrm{mg} / \mathrm{ml}$, while for the matrix 50HPC/50MAcalt-S, these values are 60 and $20 \mathrm{~min}$, respectively. Procaine hydrochloride releases much faster from matrices with a composition close to the stoichiometry of the IPC than from matrices where one of the components are in excess. For example for the matrix containing 40HPC/60MAc-alt-S the plateau 

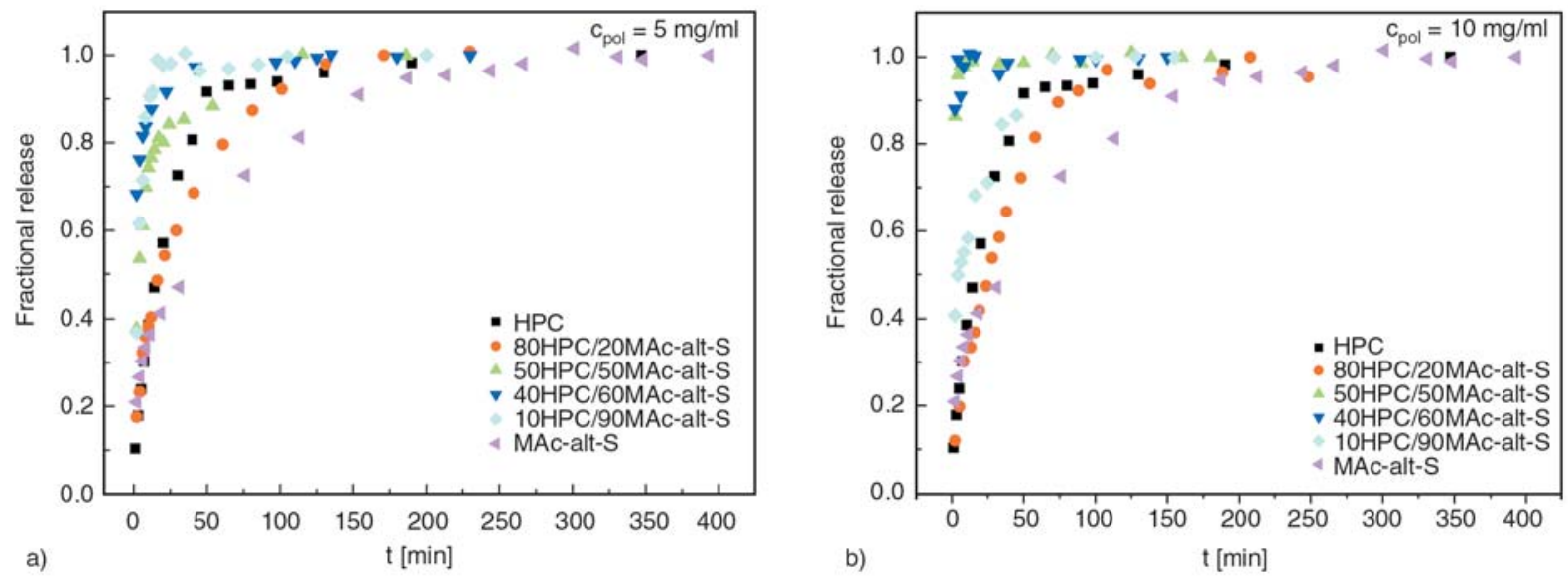

Figure 3. Release profiles of procaine hydrochloride from HPC/MAc-alt-S matrix for various ratio between components and different total polymer concentration in the initial solution: (a) $c_{p o l}=5 \mathrm{mg} / \mathrm{ml}$ and (b) $c_{p o l}=10 \mathrm{mg} / \mathrm{ml}$

is reached after about 50 minutes while for $80 \mathrm{HPC} /$ 20MAc-alt-S it takes about 175 minutes.

The similar values for the release time have been obtained by other authors from different non-covalent hydrogen bonding or polyionic interpolymeric complexes. For example using poly(vinyl alcohol)/ poly(acrylic acid), PAA interpolymer complexes release time of mucosal drug delivery was max. 60 or $30 \mathrm{~min}$ [23], PAA/Chitosan (100 min) [34], Chitosan/polyethyleneoxide-maleic acid copolymer films (max. $50 \mathrm{~min}$ ) [32]. In the last case for the polyelectrolyte complex films derived from polyethyleneoxide-maleic acid copolymer, Leong et al., found a release time of ibuprofen of maximum $30 \mathrm{~min}$ [31]. When entering into intestine, where $\mathrm{pH} \sim 7.4$ the H-bonding associations between polymer components and those between drug and polymer matrix are destroyed due to the basic $\mathrm{pH}$ and release rate and amount of the drug released will be faster and respectively higher [35-37].

The derivatives of the release profile curves, proportional with the rate of drug release, are shown in Figure 4. All show an exponential decrease with time up to 75 min then level off.

In the first 30 minutes, the release rate is very fast for all studied systems, they present the 'burst effect' and then a plateau value is reached for the entire investigated duration of the release study. One can notice that the slowest release rates is given by $10 \mathrm{HPC}$ / 90MAc-alt-S matrix, when the mixture is prepared form a solution with a $c_{p o l}=5 \mathrm{mg} / \mathrm{ml}$ and $80 \mathrm{HPC} / 20 \mathrm{MAc}-$ alt-S matrix, respectively when this is prepared from a solution with a concentration of $c_{p o l}=10 \mathrm{mg} / \mathrm{ml}$.
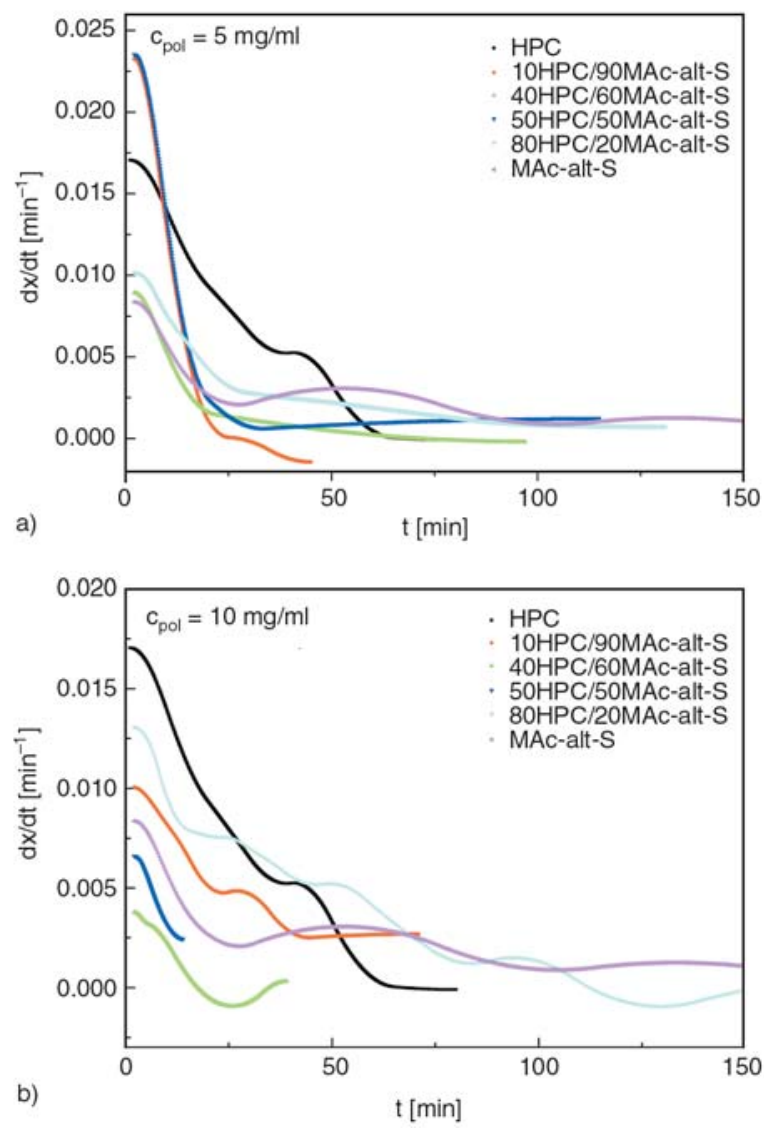

Figure 4. Derivative curves of the release profiles of procaine hydrochloride from HPC/MAc-alt-S matrix: a) $c_{p o l}=5 \mathrm{mg} / \mathrm{ml}$ and b) $c_{p o l}=10 \mathrm{mg} / \mathrm{ml}$

Kinetic analysis of our data is presented in Figures $5 \mathrm{a}$ and $5 \mathrm{~b}$ and obtained values are given in Table 3.

The kinetics of procaine hydrochloride release from HPC/MAc-alt-S matrices depends on their composition; the diffusion exponent, $n$ is close to 

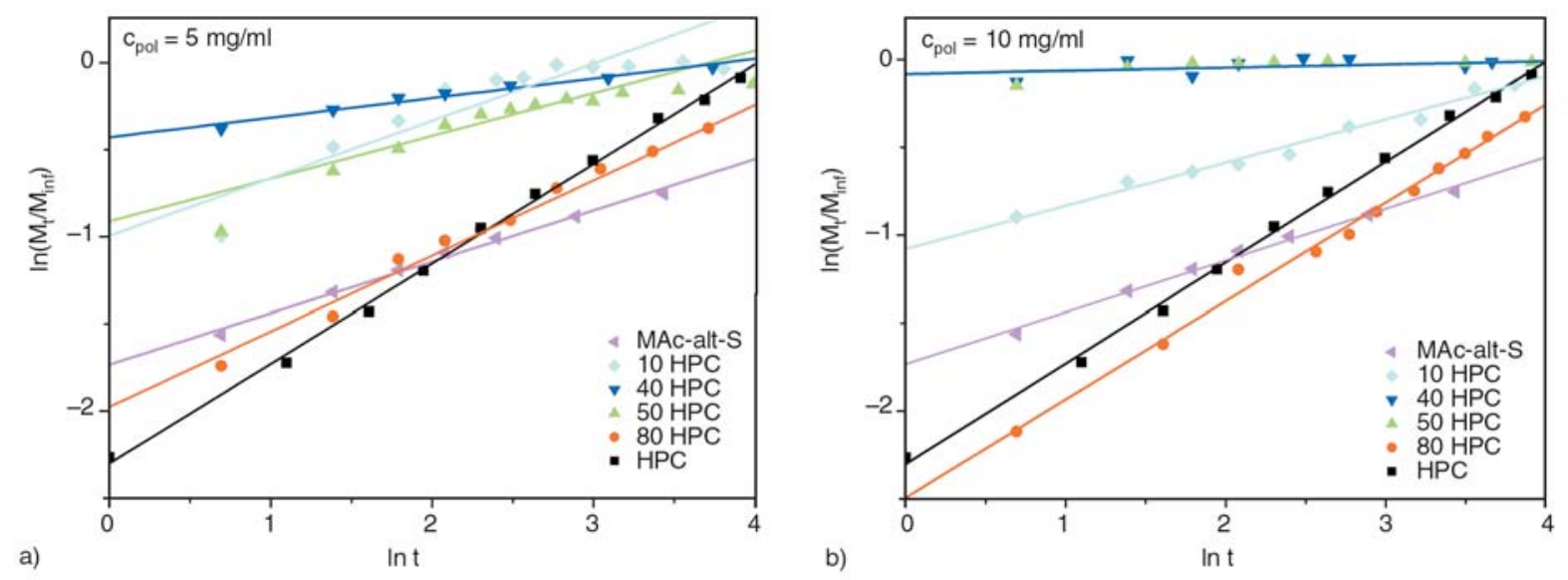

Figure 5. Graph for the evaluation of the release order: a) $c_{p o l}=5 \mathrm{mg} / \mathrm{ml}$ and b) $c_{p o l}=10 \mathrm{mg} / \mathrm{ml}$

Table 3. Values of $n$ and $k_{H}$ for various studied cases

\begin{tabular}{|l|c|c|}
\hline \multicolumn{1}{|c|}{ Sample } & $\mathbf{n}$ & $\mathbf{k}_{\mathbf{H}}\left[\mathbf{m i n}^{-\mathbf{n}}\right]$ \\
\hline \multicolumn{3}{|c|}{$c_{p o l}=5 \mathrm{mg} / \mathrm{ml}$} \\
\hline MAc-alt-S & $0.290 \pm 0.010$ & $0.177 \pm 0.005$ \\
\hline 80HPC/20MAc-alt $-\mathrm{S}$ & $0.430 \pm 0.010$ & $0.139 \pm 0.006$ \\
\hline 50HPC/50MAc-alt $-\mathrm{S}$ & $0.250 \pm 0.030$ & $0.400 \pm 0.030$ \\
\hline 40HPC/60MAc-alt -S & $0.113 \pm 0.009$ & $0.650 \pm 0.010$ \\
\hline 10HPC/90MAc-alt $-\mathrm{S}$ & $0.330 \pm 0.050$ & $0.370 \pm 0.050$ \\
\hline HPC & $0.570 \pm 0.010$ & $0.100 \pm 0.003$ \\
\hline \multicolumn{3}{|c|}{$c_{p o l}=10 \mathrm{mg} / \mathrm{ml}$} \\
\hline MAc-alt-S & $0.290 \pm 0.010$ & $0.177 \pm 0.005$ \\
\hline 80HPC/20MAc-alt $-\mathrm{S}$ & $0.560 \pm 0.020$ & $0.083 \pm 0.004$ \\
\hline 50HPC/50MAc-alt $-\mathrm{S}$ & $0.019 \pm 0.006$ & $0.920 \pm 0.020$ \\
\hline 40HPC/60MAc-alt $-\mathrm{S}$ & $0.018 \pm 0.007$ & $0.920 \pm 0.020$ \\
\hline 10HPC/90MAc-alt -S & $0.340 \pm 0.010$ & $0.250 \pm 0.010$ \\
\hline HPC & $0.570 \pm 0.010$ & $0.100 \pm 0.030$ \\
\hline
\end{tabular}

0.5 for matrix where one of the components is in large excess and $n \sim 0.02$ for middle composition range. An exception is the diffusional exponent for the release from pure MAc-alt-S. As it has been above mentioned, in this case the components form an insoluble complex.

\section{Conclusions}

The release profile of the drugs from a system that can form interpolymer association is influenced by the mixing ratio between the components and the total polymer concentration the matrix is prepared from. For compositions close to the stoichiometry of the IPC, the release drug rate is faster, while for pure MAc-alt-S it takes the longest to reach the plateau. The total polymer concentration of the HPC/MAc-alt-S solutions influences the procaine delivery release profile especially for mixture where one of the components is in excess. The delivery rate slows down after around 30-40 minutes.

\section{Acknowledgements}

The authors gratefully acknowledge financial support from Romanian ANCS and CNCSIS through PNII research project IDEI 17/2007.

\section{References}

[1] Kamel S., Ali N., Jahangir K., Shah S. M., El-Gendy A. A.: Pharmaceutical significance of cellulose: A review. Express Polymer Letters, 2, 758-778 (2008). DOI: $10.3144 /$ expresspolymlett.2008.90

[2] Anlar S., Çapan Y., Güven O., Gögüş A., Dalkara T., Hincal A. A.: Formulation and in vitro-in vivo evaluation of buccoadhesive morphine sulfate tablets. Pharmaceutical Research, 11, 231-236 (1994). DOI: 10.1023/A:1018951323522

[3] Taylan B., Çapan Y., Güven O., Kes S., Hincal A. A.: Design and evaluation of sustained-release and buccal adhesive propranolol hydrochloride tablets. Journal of Controlled Release, 38, 11-20 (1996). DOI: 10.1016/0168-3659(95)00094-1

[4] Ikinci G., Çapan Y., Senel S., Alaaddinoglu E., Dalkara T., Hincal A. A.: In vitro/in vivo studies on a buccal bioadhesive tablet formulation of carbamazepine. Pharmazie, 55, 762-765 (2000).

[5] Clausen A. E., Bernkop-Schnürch A.: Direct compressible polymethacrylic acid-starch compositions for site specific drug delivery. Journal of Controlled Release, 75, 93-102 (2001). DOI: $\underline{10.1016 / \mathrm{S} 0168-3659(01) 00366-2}$

[6] Ishida M., Machida Y., Nambu N., Nagai T.: New mucosal dosage form of insulin. Chemical and Pharmaceutical Bulletin, 29, 810-816 (1981). 
[7] Callens C., Remon J. P.: Evaluation of starch-maltodextrin-Carbopol ${ }^{\circledR}$ 974P mixtures for the nasal administration. Journal of Controlled Release, 66, 215-220 (2000).

DOI: $10.1016 / \mathrm{S} 0168-3659(99) 00271-0$

[8] Nurkeeva Z. S., Khutoryanskiy V. V., Mun G. A., Sherbakova M. V., Ivaschenko A. T., Aitkhozhina N. A.: Polycomplexes of poly(acrylic acid) with streptomycin sulfate and their antibacterial activity. European Journal of Pharmaceutics and Biopharmaceutics, 57, 245-249 (2004). DOI: $10.1016 / \mathrm{S} 0939-6411(03) 00149-8$

[9] Nurkeeva Z. S., Mun G. A., Khutoryanskiy V. V.: Interpolymer complexes of water-soluble nonionic polysaccharides with polycarboxylic acids and their applications. Macromolecular Bioscience, 3, 283-295 (2003).

DOI: $10.1002 /$ mabi.200390037

[10] Callens C., Adriaens E., Dierckens K., Remon J. P.: Toxicological evaluation of a bioadhesive nasal powder containing a starch and $\mathrm{Carbopol}^{\circledR} 974 \mathrm{P}$ on rabbit nasal mucosa and slug mucosa. Journal of Controlled Release, 76, 81-91(2001).

DOI: $\underline{10.1016 / \mathrm{S} 0168-3659(01) 00419-9}$

[11] Ozeki T., Yuasa H. and Okada H.: Controlled release of drug via methylcellulose-carboxyvinylpolymer interpolymer complex solid dispersion. AAPS PharmSciTech, 6, E231-E236 (2005).

DOI: $10.1208 / \mathrm{pt} 060233$

[12] Kumar S., Himmelstein K. J.: Modification of in situ gelling behavior of carbopol solutions by hydroxypropyl methylcellulose. Journal of Pharmaceutical Sciences, 84, 344-348 (1995).

DOI: $10.1002 / j p s .2600840315$

[13] Srividya B., Cardoza R. M., Amin P. D.: Sustained ophthalmic delivery of ofloxacin from $\mathrm{pH}$ triggered in situ gelling system. Journal of Controlled Release, 73, 205-211 (2001).

DOI: 10.1016/S0168-3659(01)00279-6

[14] Nurkeeva Z. S., Mun G. A., Khutoryanskiy V. V.: Interpolymer complexes of water-soluble non-ionic polysaccharides with polycarboxylic acids and their applications. Macromolecular Bioscience, 3, 283-295 (2003).

DOI: $10.1002 / \mathrm{mabi} .200390037$

[15] Khutoryanskiy V. V., Cascone M. G., Lazzeri L., Nurkeeva Z. S., Mun G. A., Mangazbaeva R. A.: Phase behavior of methylcellulose-poly(acrylic acid) blends and preparation of related hydrophilic films. Polymer International, 52, 62-67 (2003). DOI: $10.1002 /$ pi.1004

[16] Satoh K., Takayama K., Machida Y., Suzuki Y., Nakagaki M., Nagai T.: Factors affecting the bioadhesive property of tablets consisting of hydroxypropyl cellulose and carboxyvinyl polymer. Chemical and Pharmaceutical Bulletin, 37, 1366-1368 (1989).
[17] Bumbu G-G., Eckelt J., Vasile C., Wolf B. A.: Interpolymer complex between hydroxypropyl cellulose and maleic acid-styrene copolymer: Phase behavior of semi-dilute solutions. Macromolecular Bioscience, 5, 936-940 (2005).

DOI: $10.1002 / \mathrm{mabi} .200500070$

[18] Bumbu G. G., Vasile C., Eckelt J., Wolf B. A.: Investigation of the interpolymer complex between hydroxypropyl cellulose and maleic acid-styrene copolymer, I. Dilute solutions studies. Macromolecular Chemistry and Physics, 205, 1869-1876 (2004). DOI: $\underline{10.1002 / \mathrm{macp} .200400253}$

[19] Bumbu G. G., Vasile C., Chitanu G. C., Staikos G.: Interpolymer complexes between hydroxypropylcellulose and copolymers of maleic acid: A comparative study. Macromolecular Chemistry and Physics, 206, 540-546 (2005).

DOI: $10.1002 / \mathrm{macp} .200400489$

[20] Baker R. W.: Membrane technology and applications. McGraw-Hill, New York (2000).

[21] Schloss P., Williams C. D.: The serotonin transporter: A primary target for antidepressant drugs. Journal of Psychopharmacology, 12, 115-121 (1998).

DOI: $\underline{10.1177 / 026988119801200201}$

[22] Halkes S. B. A.. Van den Berg A. J. J., Hoekstra M. J., Du Point J. S., Kreis R. W.: The use of tannic acid in the local treatment of burn wounds: Intriguing old and new perspectives. Wounds, 13, 144-158, (2001).

[23] Technical Bulletin. Aqualon, a Division of Hercules Inc (1990).

[24] Chitanu G. C., Bumbu G. G., Carpov A., Vasile C.: Analysis and characterisation of maleic anhydride copolymers. II. Some aspects of thermo-oxidative decomposition. International Journal of Polymer Analysis and Characterization, 4, 479-500 (1998). DOI: $10.1080 / 10236669808009730$

[25] Oh J-M., Cho C-S., Choi H-K.: A mucoadhesive polymer prepared by template polymerization of acrylic acid in the presence of poly(vinyl alcohol) for mucosal drug delivery. Journal of Applied Polymer Science, 94, 327-331 (2004).

DOI: $10.1002 / a p p .20911$

[26] Higuchi T.: Rate of release of medicaments from ointment bases containing drugs in suspension. Journal of Pharmaceutical Sciences, 50, 874-875 (1961). DOI: $\underline{10.1002 / j p s .2600501018}$

[27] Gohel M. C., Panchal M. K., Jogani V. V.: Novel mathematical method for quantitative expression of deviation from Higuchi model. AAPS PharmSciTech, 1, 43-48 (2000). DOI: $10.1208 / \mathrm{pt} 010431$

[28] Ritger P. L., Peppas N. A.: A Simple equation for description of solute. Release I. Fickian and anomalous release from non-swellable devices in the form of slabs, spheres, cylinders or discs. Journal of Controlled Release, 5, 23-36 (1987). DOI: $\underline{10.1016 / 0168-3659(87) 90034-4}$ 
[29] Chen J., Sun J., Yang L., Zhang Q., Zhu H., Wu H., Hoffman A. S., Kaetsu I.: Preparation and characterization of a novel IPN hydrogel memberane of $\operatorname{poly}(\mathrm{N}$ isopropylacrylamide)/carboxymethyl chitosan (PNIPAAM/CMCS). Radiation Physics and Chemistry, 76, 1425-1429 (2007).

DOI: $10.1016 /$ j.radphyschem.2007.02.045

[30] Peppas N. A.: Analysis of Fickian and non-Fickian drug release from polymers. Pharmaceutica Acta Helvetiae, 60, 110-111 (1985).

[31] Peppas N. A.: Hydrogels in medicine and pharmacy. CRC Press, Boca Raton (1986).

[32] Peppas N. A., Sahlin J. J.: A simple equation for the description of solute release. III. Coupling of diffusion and relaxation. International Journal of Pharmaceutics, 57, 169-172 (1989).

DOI: $\underline{10.1016 / 0378-5173(89) 90306-2}$

[33] Shin-Ya Y., Tsurushima H., Tsurumi T., Kajiuchi T., Leong K. W.: Polyelectrolyte complex films derived from polyethyleneoxide-maleic acid copolymer and chitosan: Preparation and characterization. Macromolecular Bioscience, 4, 526-531 (2004).

DOI: $10.1002 / \mathrm{mabi} .200300110$
[34] de la Torre P. M., Torrado S., Torrado S.: Interpolymer complexes of poly(acrylic acid) and chitosan: Influence of the ionic hydrogel-forming medium. Biomaterials, 24, 1459-1468 (2003).

DOI: $10.1016 / \mathrm{S} 0142-9612(02) 00541-0$

[35] Peh K-K., Yuen K-H.: Development and in vitro evaluation of a novel multiparticulate matrix controlled release formulation of theophylline. Drug Development and Industrial Pharmacy, 21, 1545-1555 (1995). DOI: $10.3109 / 03639049509069244$

[36] Korsmeyer R. W., Gurny R., Doelker E., Buri P., Peppas N. A.: Mechanisms of solute release from porous hydrophilic polymers. International Journal of Pharmaceutics, 15, 25-35 (1983). DOI: $\underline{10.1016 / 0378-5173(83) 90064-9}$

[37] Kubo W., Miyazaki S., Attwood D.: Oral sustained delivery of paracetamol from in situ-gelling gellan and sodium alginate formulations. International Journal of Pharmaceutics, 258, 55-64 (2003). DOI: $\underline{10.1016 / \mathrm{S} 0378-5173(03) 00163-7}$ 